\title{
Rebelde(s): consumo e valores nas telenovelas brasileira e mexicana ${ }^{1}$
}

Maria Aparecida Baccega

Livre-docente em Comunicação pela Escola de Comunicações e Artes da USP. Docente, pesquisadora e orientadora do Programa de Pós-graduação em Comunicaşão e Práticas de Consumo da Escola Superior de Propaganda e Marketing (SP). Pesquisadora do Centro de Pesquisa de Telenovela (USP), do Centro de Pesquisa Comunicaşão e Trabalho (USP) e do OBITEL (Observatório Ibero-americano de Ficção Televisiva).

E-mail: mabga@usp.br

Fernanda Elouise Budag

Mestre em Comunicação e Práticas de Consumo pela Escola Superior de Propaganda e Marketing (ESPM-SP). Graduada em Comunicação Social - Publicidade e Propaganda, pela Universidade Regional de Blumenau (FURB). Docente da Faculdade Paulus de Tecnologia e Comunicaşão (FAPCOM) e da Faculdade IBTA.

E-mail: fernanda.budag@gmail.com

Lucas Máximo Ribeiro

Graduando em Comunicaşão Social - Publicidade e Propaganda, pela Escola Superior de Propaganda e Marketing (ESPM-SP). Auxiliar de pesquisa do Programa de Suporte à Pós-graduação de Instituições de Ensino Particulares (PROSUP).

E-mail: lucasmaximo@gmail.com

Resumo: Partindo de duas pesquisas que se debruçaram sobre produtos midiáticos afins - Rebelde (veiculada no Brasil entre 2006-2007) e Rebeldes (2011) -, lançamos mão de seus discursos e buscamos traçar conexões sobre questões relacionadas a consumo, a temáticas centrais em pauta em ambas as telenovelas e a valores prezados por seus respectivos sujeitos receptores.

Palavras-chave: Comunicação; consumo, telenovela; discurso; recepção.
Abstract: From two researches that examine the same media product - Rebelde (aired in Brazil between 2006-2007) and Rebeldes (2011-present), we investigate their discourses and try to outline connections about issues related to consumption, to central topics concerning the two programs and to values appreciated by their reception subjects.

Keywords: communication; consumption; telenovela; discourse; reception.

\section{INTRODUÇÃO}

Enxergamos a telenovela como grande observatório do cenário sociocultural de uma época, das práticas em voga, dos valores em evidência e dos temas em destaque e em discussão na sociedade. Esse fenômeno acontece em especial no

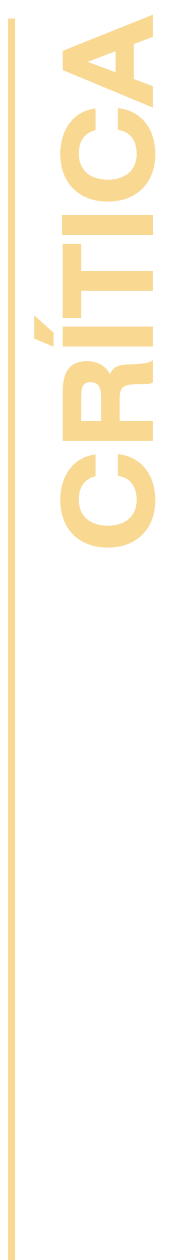

Recebido: 11/09/2012

Aprovado: 30/10/2012

1. Artigo resultante do cruzamento de duas pesquisas, ambas sob orientação de Dra. Maria Aparecida Baccega: BUDAG, Fernanda Elouise. Comunicação, recepção e consumo: suas inter-relações em Rebelde-RBD. Dissertação (Programa de Pós-graduação em Comunicação e Práticas de Consumo) - Escola Superior de Propaganda e Marketing, ESPM, 2008; RIBEIRO, Lucas Máximo. Rebeldes. Pesquisa de iniciação científica (Programa de Pós-graduação em Comunicação e Práticas de Consumo) - Escola Superior de Propaganda e Marketing, ESPM, 2011. 
comunicação \& educação • Ano XV|ll • número 1 • jan/jun 2013

Brasil, quando levamos em conta que a televisão é a principal fonte de informação e lazer para uma parcela de brasileiros menos privilegiada monetariamente, das classes D e E - sem acesso a TV a cabo, teatro, cinema, revistas, viagens e demais experiências que enriquecem visões de mundo, repertórios e mesmo a bagagem de conhecimentos gerais. Nesse contexto, a telenovela figura como importante referência de estilos de vida, gostos e padrões estéticos, bem como de identificação e/ou aspiração de consumo. E, quando pensamos na tão aclamada "nova classe C" - sujeitos que subiram na pirâmide social nos últimos anos em virtude da profunda mudança na economia brasileira, que culminou em elevação de renda -, estamos falando de pessoas que, até há apenas menos de uma década, viviam com o básico do básico e hoje possuem recursos extras que lhes permitem ter luxos e fazer extravagâncias. Ou seja, essa porção da população se junta à classe média que, pela primeira vez na história do país, representa mais da metade da população: 170 milhões de consumidores. Consumidores/cidadãos. Em referência direta a Canclini, "podemos atuar como consumidores nos situando somente em um dos processos de interação - o que o mercado regula - e também podemos exercer como cidadãos uma reflexão e uma experimentação mais ampla que leve em conta as múltiplas potencialidades dos objetos [...]"2.

Desse novo cenário econômico-social brasileiro emerge o desejo - e, por que não, a necessidade - de atualização do universo de investigação em torno da telenovela Rebelde (mexicana, veiculada no Brasil entre 2006 e 2007), a partir de cruzamentos com sua versão mais recente, ainda em transmissão - a brasileira Rebeldes, no ar, pela Rede Record, em 2011.

Destacamos que, em contraste com toda a paisagem econômica e social que viemos apontando, ambas as telenovelas possuem como palco principal de suas histórias uma escola de nome Elite Way, voltada à alta classe social, aos ricos e famosos. Porém, ambas as escolas retratadas, em contrapartida, possuem sistemas de bolsas de estudo que possibilitam aceitar alunos de menor renda.

Interessa-nos aproximar e distanciar as telenovelas - a matriz mexicana e a versão brasileira - na tentativa de identificação de questões relacionadas ao consumo e, no que concerne ao discurso, aos valores e temas recorrentes em

2. CANCLINI, Néstor García. Consumidores e cidadãos: conflitos multiculturais da globalização. Rio de Janeiro: Editora UFRJ, 2006. p. 71.

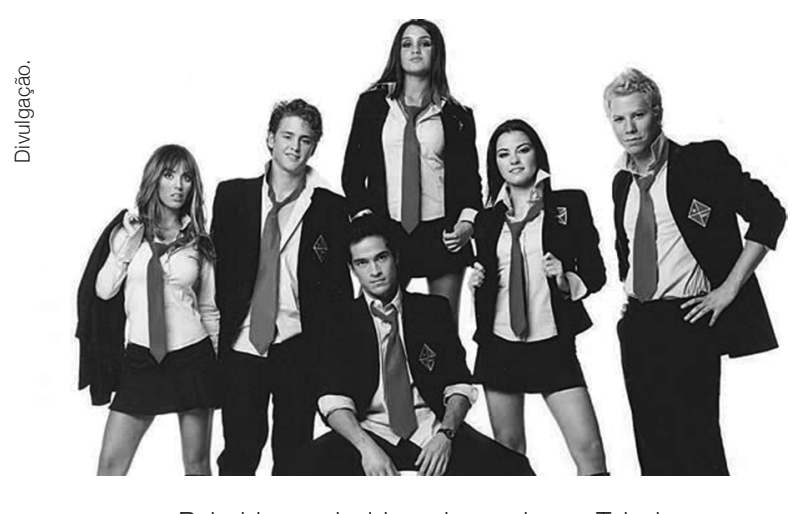

Rebelde produzido pela mexicana Televisa. cada uma delas.

\section{REBELDE: O ORIGINAL MEXICANO}

Rebelde, produção da mexicana Televisa, trabalhou com estereótipos e assuntos interesse universal a ponto de arrebatar públicos em mais de 70 países - e de culturas, em 
alguns casos, extremamente diversas, como México, Chile, Colômbia, Estados Unidos, Peru, Venezuela, Espanha, Angola, República Dominicana, Israel, Canadá, Rússia, Índia, Inglaterra e Japão.

\section{valores na trama}

Iniciamos com a apresentação e análise dos principais valores que reconhecemos no discurso - imagético e oral - de Rebelde, a partir de recorrências temáticas. Assistindo aos DVDs das três temporadas da telenovela, identificamos, sobretudo, quatro valores principais que permeiam toda a trama, quais sejam: amizade, amor, família e rebeldia. Vejamos algumas representações desses valores.

\section{A) Amizade}

Exemplificamos a expressão do valor Amizade com o discurso que encerra o capítulo final da terceira temporada - comprovando que se trata de um tema ao qual a telenovela deseja dar importância. Oralizada em retrospectiva, na voz de sete dos principais alunos do Colégio - isto é, integrantes do núcleo central da trama -, a mensagem é a seguinte:

Não sei se o Colégio era exatamente como me lembro. Ou se os professores eram tão bons ou tão ruins como ficaram na minha memória. O que eu sei é que o mais importante que eu aprendi naqueles dias foi o valor da amizade. Os amigos sempre presentes, para o bem ou para o mal. Nos melhores e nos piores momentos. São deles [sic] que eu me lembro com maior nitidez. E o amor? O primeiro amor. Amores, amigos, não importa como ou onde estejam, sempre os levo comigo. E eu sei que vou com eles. Porque naquilo que somos hoje, está presente o que fomos. A vocês, meus amigos do coração, não me canso de agradecer, sempre. Porque naquela época em que caminhávamos no mundo de coração aberto, conseguimos fazer do mundo um lugar melhor para se viver.

Como percebemos, a temática da amizade perpassa boa parte desse discurso. Percebemos a presença da "formação discursiva" no trecho final dessa fala, quando o sujeito fala na posição de ex-aluno do Colégio - "naquilo que somos hoje está presente o que fomos". Se outra fosse sua posição, a fala obedeceria a uma formação discursiva diferente.

\section{B) Rebeldia}

A respeito de "rebeldia", trazemos o discurso do professor Madariaga personagem do núcleo central da trama, bastante querido dos alunos, que fica ausente durante a trama para reaparecer no final:

[Vocês, alunos] mostraram uma união, como grupo, incrível. Me surpreenderam. E mais uma vez enfrentaram tudo para defender a um de vocês. A uma de vocês, nesse caso. [...] O melhor de tudo... o melhor de tudo, gente, é que, por trás dessa rebeldia de vocês, mostraram ter valores muito fortes. Muito fortes. Eu sei que no dia de amanhã essa força vai fazer com que possam mudar muitas
3. Ou seja, o conjunto de regras que regulam os discursos, de acordo com posições ocupadas e com contextos históricos determinados (MAINGUENEAU, Dominique. Termos-chave da análise do discurso. Belo horizonte: Ed. UFMG, 1998. p. 68). 
comunicação \& educação • Ano XVIII • número 1 • jan/jun 2013

coisas. E ainda que cresçam (acreditem, vai acontecer). Não percam isso, gente. De verdade. Não percam essa rebeldia, mas sempre com razão e com o coração.

O personagem aparece como um ponto positivo da telenovela, pois - não somente nesse episódio, mas em outros - profere falas dirigidas a situações de mudança.

A telenovela defende a necessidade de os jovens terem uma postura pró-ativa, o que é visto de forma positiva. Contudo, analisando esta cena conjuntamente com as demais cenas de Rebelde, percebemos que a trama sustenta a "rebeldia" em relação a causas que se restringem à esfera escolar ou à esfera pessoal dos jovens - não se aprofundando, portanto, na macroestrutura social. Geralmente, conforme se desenrolam as histórias no transcorrer da telenovela, percebe-se que as causas da "rebeldia" - de nível micro - são as injustiças que ocorrem com um ou outro colega. Na situação anterior, a injustiça era com relação à expulsão de uma aluna grávida.

A partir de resultados de pesquisa de campo, concluímos que tanto Rebelde quanto seus receptores operaram uma ressignificação do conceito de rebeldia, ao retirarem a carga de revolta que o adjetivo "rebelde" possui em sua origem. A rebeldia, que até então remetia à tentativa de mudança da macroestrutura e à ida de encontro à autoridade constituída, na busca de modificação profunda dos valores da sociedade, passa a ser uma revolta que se esgota na microestrutura - no âmbito da família e da escola.

\section{Amor}

Já sobre o conceito de "amor", percebemos na telenovela duas posturas que se complementam: a primeira é de luta para manter um relacionamento, e a segunda é de hipervalorização do amor. Um discurso de Roberta - personagem que faz parte do núcleo central, indisciplinada e teimosa, e que é a representante maior da "rebeldia" propagada pela obra - sintetiza este posicionamento diante do amor:

Bom, estamos aqui para festejar algo pelo qual vocês têm lutado com todas as forças. Estamos aqui para celebrar o amor! (suspiro). Lupita e Nico se apaixonaram... e esperaram... fizeram mil coisas pra ficarem juntos e nós sabemos disso. E, na verdade, eu acho que ver que nada e nem ninguém pode separá-los foi o melhor que pôde acontecer no Colégio, neste ano que estivemos juntos (suspiro). Por isso eu, que sou uma rebelde, e que hoje tenho a honra e a sorte de representar os rebeldes do mundo (pausa)... quero pedir para lembrarmos algo muito importante e que a maioria dos adultos já se esqueceu. Que o amor é o mais importante e o mais forte que existe no mundo. E por isso estamos aqui! [...] Bom, pois, agora, sim, diante das leis da natureza, da liberdade e do amor, nós todos os declaramos marido e mulher! O que os amigos unem, nada e ninguém pode separar.

Roberta na ocasião ocupa a posição de "mestre de cerimônias" em uma celebração, sem valor legal ou religioso, que os amigos preparam para o casamento 
de Nico e Lupita. Observando os não ditos - ou implícitos -, podemos notar, principalmente pelo trecho "fizeram mil coisas pra ficarem juntos", que o casal passou por situações que colocaram à prova o seu amor - possivelmente, de pessoas que tramaram situações para colocar um contra o outro ou separá-los. Expressões e palavras como "única coisa que salva", "única coisa que fica", "celebrar", "festejar", "o mais importante" e "o mais forte" são todas indicativas da posição de celebração do amor, que Rebelde veicula.

\section{D) Família}

Como na maioria das telenovelas - e no cotidiano real, sua matéria-fonte -, em Rebelde a família assume papel importante. Mesmo sendo retratada, por vezes, como origem de sofrimentos, na trama ela também assume o papel de fonte de felicidade. Vejamos, então, um discurso típico de cada um dos casos. Sobre o primeiro (sofrimento), em uma fala da personagem Roberta, notamos seu desapontamento com relação à família:

O mundo não é nada como falam. Essa casinha de boneca com uma família que demonstra tudo que se quer. Isso só existe nas brincadeiras. Na vida real, a família é um grupo de desconhecidos, que só pensam em sobreviver. Quando não é possível mais acreditar nos próprios pais, o que sobra? Tudo uma grande mentira. E eu não quero ser parte disso. Agora eu vou fazer tudo o que eu quiser. Vou fazer tudo o que me disseram pra não fazer.

Já sobre a segunda abordagem (felicidade), temos um discurso de Franco Colucci, um personagem positivo que, apesar de não estar ligado diretamente ao Elite Way School, insere-se no núcleo central de Rebelde: "Eu quero dizer que quem está agradecido sou eu. Eu era um homem só, na minha solidão. Eu quero dizer que devo agradecer à vida porque graças a vocês a minha vida se converteu em luz e alegria de viver. Obrigado". O contexto da enunciação é o momento que antecipa o casamento de Franco - empresário do ramo da moda, muito rico, pai da aluna Mia - com Alma Rey (mãe de Roberta). Nesta fala, Franco agradece Alma, Mía (sua filha), Roberta (filha de Alma) e Josy (amiga de Roberta e Mía que foi adotada pelo casal) por iluminarem sua vida. Dessa forma, no que se refere à família, constatamos a presença da polissemia (multiplicidade de sentidos): "família" gerando sentidos positivos e negativos.

\section{consumo: sentidos}

Pensando na inter-relação entre discurso de valores e práticas de consumo, buscamos notar a emergência dos sentidos criados e/ou reproduzidos nos discursos pronunciados pelos receptores de Rebelde, abordados em nossa pesquisa ${ }^{4}$, tendo em vista que "os dizeres não são [...] apenas mensagens a serem decodificadas. São efeitos de sentidos que são produzidos em condições determinadas e que estão de alguma forma presentes no modo como se diz [...]"
4. Pesquisa de campo de abordagem multimetodológica empreendida junto a jovens receptores de Rebelde, por meio de abordagens no show de RBD, questionários quanti-qualitativos, grupo focal e entrevistas em profundidade.

5. ORLANDI, Eni Puccinelli. Análise de discurso; princípios e procedimentos. Campinas: Pontes, 2007. p. 30. 
comunicação \& educação • Ano XV|l| • número 1 • jan/jun 2013

Para esta etapa, após estudarmos procedimentos possíveis de análise, optamos pela proposta de Fiorin ${ }^{6}$, segundo o qual a formação discursiva "[...] é um conjunto de temas e de figuras que materializa uma dada visão de mundo"7, onde "tema é o elemento semântico que designa um elemento não presente no mundo natural, mas que exerce o papel de categoria ordenadora dos fatos observáveis"; e figura, por sua vez, "[...] é o elemento semântico que remete a um elemento do mundo natural [...]" . Assim, nosso procedimento de análise consistiu-se em desconstruir os discursos dos receptores de Rebelde, dos quais nos aproximamos com o intuito de identificar temas e figuras para, então, registrarmos aqui os sentidos emergidos.

Selecionamos, para trabalhar neste pequeno espaço, uma questão que parece resumir o diálogo que os receptores mantêm com esta telenovela e o grupo musical a ela vinculado. Na tentativa de percebermos como os receptores de Rebelde- $R B D$ racionalizam e verbalizam o afeto que sentem por estes ídolos e pelos produtos midiáticos por eles protagonizados, questionamos sobre "o que tem a novela Rebelde que dá vontade aos receptores de comprar os produtos?".

Encontramos então o afeto tematizado em quatro âmbitos: visual, conteudístico, material e emocional. O tema no âmbito visual é figurativizado pelos seguintes elementos: a beleza e o "jeito" dos atores/músicos; o quarto das personagens da telenovela; e as roupas, uniformes e acessórios por eles usados. No âmbito conteudístico, o tema aparece figurativizado como "é uma novela que ensina muito". O âmbito material, por sua vez - referindo-se, mais diretamente, à posse de bens materiais (produtos) -, é figurativizado em sentenças como esta: "é legal ter os produtos para mostrar para os outros". Já no âmbito emocional, o tema aparece figurativizado nos enunciados que seguem: "é para ter a coleção de tudo deles para vê-los todos os dias, toda hora e todo o momento", "parece que eles são viciantes", "porque eles mexem com a nossa cabeça", "nos atrai por ser parecido com a gente".

6. FIORIN, José Luiz. O regime de 1964: discurso e ideologia. São Paulo: Atual, 1988; Id. Linguagem e ideologia. São Paulo: Ática, 2005.

7. Id. Linguagem e ideologia, cit., p. 32.

8. Ibid., p. 24.

9. Ibid., p. 24.

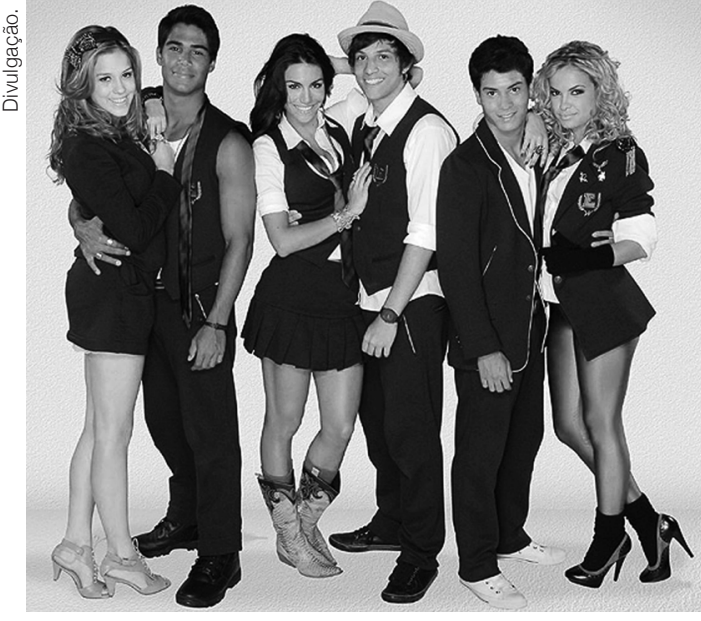

A versão brasileira, produzida pela Rede Record.

\section{REBELDES: VERSÃO BRASILEIRA}

Conforme adiantamos na introdução, damos continuidade a este estudo por meio do processo de exploração de outro universo, distinto, mas complementar: o mundo ficcional de Rebeldes, produção nacional da Rede Record - cuja veiculação, iniciou-se em 21 de março de 2011.

Inspirada diretamente na versão mexicana de que tratávamos há pouco - daí nosso interesse em aproximá-las -, seu enredo assemelha-se bastante ao de sua antecessora, mantendo os 
nomes de alguns personagens, a identificação da escola e a formação dos casais. No entanto, a telenovela nacional traz uma edição mais dinâmica e diálogos mais rápidos entre as personagens - e, por mais que haja também uma banda composta de alguns estudantes do colégio, esta recebe um nome diferente da anterior, batizada agora de Rebeldes - o mesmo nome da telenovela (diferindo da dupla Rebelde-RBD no México).

\section{s valores na trama}

Assim como procedemos com o produto midiático anterior, em Rebeldes procuramos identificar os valores abordados na trama de forma mais recorrente, seja em discursos e representações orais ou imagéticos. A maior parte dos temas coincide com os da versão mexicana, justamente porque seu enredo - de sucesso anterior - foi praticamente mantido.

\section{A) Família}

Como ocorria no original mexicano, a questão familiar é também retratada com bastante frequência na produção brasileira, principalmente devido ao fato de os estudantes do colégio viverem em sistema de semi-internato - o que potencializa a saudade que sentem de seus familiares. Os pais dos personagens são, em sua grande maioria, profissionais bem-sucedidos e ocupados demais no trabalho, o que acarreta em falta de tempo para ver seus filhos. A personagem Alice, por exemplo, deixa claro em um discurso seu descontentamento com o fato de nunca ver seu pai e tampouco contar com sua colaboração: "Do que adianta ser a garota mais popular do colégio e não ter o apoio do meu pai nunca?". Embora a telenovela apresente o relacionamento conflitante entre pais e filhos, a busca de consenso entre as duas partes está sempre presente.

\section{B) Rebeldia}

Quanto à rebeldia, o discurso de alguns alunos num protesto coletivo contra o diretor revela o significado que esse valor/tema tem para a telenovela. Pedro: "Ser rebelde é ser você mesmo e não respeitar as regras só porque elas são regras". Roberta: "Ser rebelde é pensar com a sua própria cabeça". Alice: "Ser rebelde é fazer aquilo que você acredita". Thomas: "Ser rebelde não é só ser 'do contra', ser rebelde é fazer o que acha certo". Carla: "Ser rebelde é não aceitar imposição". Diego: "Ser rebelde é questionar". E, na continuidade dessa mesma cena, o professor Vicente traz o seguinte discurso: "Vocês se lembram do que eu disse sobre ser rebelde? Que ser rebelde é não aceitar imposição, é não aceitar o que vem de fora e sim entender e fazer? Porque o movimento vem de dentro, vem do entendimento". O discurso é, pois, apoiado e legitimado por uma autoridade competente, um professor. 


$$
\text { comunicação \& educação • Ano XVIII • número } 1 \text { • jan/jun } 2013
$$

É possível identificar, em seu discurso, a defesa da "rebeldia" como apelo para que cada aluno tenha conhecimento de si próprio - para, então, compreender o que acontece ao redor e, somente assim, tomar atitudes com justiça e ética.

\section{C) Amor}

Novamente, o amor é mais um dos valores presentes na telenovela, sendo argumento que induz a desfechos ao longo de Rebeldes.

(...) Existe um nome específico para a mistura de coisas diferentes: criatividade. Ser criativo é pegar duas coisas que aparentemente não tem nada a ver e combinar numa coisa nova. Igual para igual: mais do mesmo. Diferente com diferente, alguém sabe? É o novo, original, criativo. A mistura de coisas diferentes gera o novo. Pega duas pessoas iguaizinhas, que pensam do mesmo jeito, que gostam das mesmas coisas, pode parecer confortável e legal no começo, mas depois... começa a enjoar, isso não cresce, não desenvolve, é mais do mesmo. Agora pega duas pessoas apaixonadas! Que não têm nada a ver! Nada! Absolutamente nada a ver uma com a outra! (...) O que pode surgir? (...) Pode surgir algo novo, troca de valores, crescimento, aprendizado.

A citação foi tirada do discurso do professor Vicente sobre o amor. Podemos perceber, claramente, que a fala é coerente com o relacionamento amoroso vivenciado pelos casais que fazem parte do núcleo central da telenovela, uma vez que todos apresentam alguma - grande ou sutil - diferença em relação ao seu parceiro. Alice, por exemplo, é menina rica e popular, enquanto Pedro, seu namorado, é de família humilde e estuda como bolsista no Elite Way.

\section{D) Dinheiro}

O valor do dinheiro é uma constante em Rebeldes - sendo a questão monetária frequentemente figurativizada. A personagem Alice, por exemplo, sabe usar isso a seu favor. Para confortar a bolsista Vitória, após descumprirem as regras do colégio, Alice diz "relaxa que não vai acontecer nada, porque pelo que eu vi a família do Tomás tem grana e a minha também (...) e grana nesse colégio tão formal e sério significa benefícios".

Vitória, por sua vez, sonha em se casar com um homem rico e fica bastante feliz ao conseguir a bolsa no Elite Way College: "Imagina eu naquele colégio, cheio de meninos ricos".

\section{consumo: práticas}

$\mathrm{Na}$ esfera do consumo - primeiramente, em relação ao universo da produção, ou seja, da oferta de bens de consumo relacionados à trama - identificamos um nicho muito bem explorado em torno de Rebeldes. Obviamente, os produtores tinham como referência o sucesso que a versão mexicana da telenovela alcançou entre seus receptores/consumidores, vislumbrando com tranquilidade, portanto, as mesmas - ou maiores - oportunidades no Brasil. 
Dados obtidos projetavam o lançamento, pela Record Entretenimento, de 47 categorias diferentes de produtos licenciados com a marca da trama, com foco principal em materiais escolares e $\mathrm{CDs}^{10}$.

Entre os itens mais desejados entre os receptores/consumidores, ao lado de pôsteres, revistas e CDs, está uma linha inteira de esmaltes da marca Impala inspirada na telenovela - trazendo cores vibrantes que seguem a moda do chamado color blocking. Outra grande aposta dos produtores é o livro Rebeldes - A obra oficial, que, tal qual a publicação similar de sua antecessora, apresenta imagens, entrevistas com os atores e perfis dos personagens. Brinquedos, bicicletas, chicletes, pulseiras e demais acessórios também entram na lista de produtos à disposição no mercado.

Porém, o que mais chama a atenção em se tratando de consumo em Rebeldes, agora a respeito dos consumidores propriamente ditos - que, na era digital, agregam a função simultânea de produtores de informação -, é a introdução de uma nova prática de consumo de telenovela: o compartilhamento dos gostos e temáticas pelas redes sociais. Estas possibilitam a visibilidade tão desejada - e, por que não, até mesmo exigida - na contemporaneidade e permitem a formação de redes, comunidades, agrupamentos que compartilham interesses afins. "A Web 2.0 tem repercussões sociais importantes, que potencializam processos de trabalho coletivo, de troca afetiva, de produção e circulação de informações, de construção social de conhecimento apoiada pela informática"11.

No caso de Rebeldes, destacamos, especificamente, a interação por meio da rede social Twitter. Uma evidência dessa (re)produção de conteúdo e de manifestação de afeto por parte dos fãs da telenovela é que as chamadas hashtags ${ }^{12}$ relacionadas a Rebeldes vêm figurando, por diversas ocasióes, entre os chamados Trending Topics ${ }^{13}$ (TTs) da rede social. Entre as hashtags mais significativas em termos de quantidade de menções, encontramos "Pedro e Alice" (um casal da trama), "Pelice" (termo que junta sílabas dos nomes do casal supracitado), "Vicente Antonio" (personagem), "EuAmoRebeldes" e "Depois da chuva" (uma música da banda).

Esses são reflexos dos novos padrões de consumo da telenovela: temos um produto cultural-midiático legitimamente nacional moldando-se a um novo cenário, permeado por tecnologias digitais que, ao mesmo tempo que se alimentam da telenovela, também a renovam e a fomentam.

\section{REFLEXÕES FINAIS}

Conforme assinalamos no início, até mesmo como justificativa para os presentes relatos e reflexões, vivemos hoje, no Brasil, num cenário socioeconômico e tecnológico já bastante diferente e distante dos anos de 2006-2007, período de transmissão da Rebelde mexicana.

Portanto, a partir da aproximação desta com a Rebeldes brasileira, acreditamos ter lançado luz sobre permanências e rupturas em torno de tematizações
10. NA TELINHA. Record lançará linha de produtos de "Rebelde". Disponível em: <http:// natelinha.uol.com.br/noticias/2011/03/16/154442. php>. Acesso em: 16 mar. 2011.

11. PRIMO, Alex. O aspecto relacional das interações na Web 2.0. In: XXIX CONGRESSO BRASILEIRO DE CIÊNCIAS DA COMUNICAÇÃO. Brasília, Anais, 2006. p. 2.

12. Termo utilizado para denominar um tópico que se deseja fazer ser indexado pelo Twitter, acrescentando-se o símbolo "\#" à sua frente.

13. Trending Topis são os assuntos mais citados em determinado momento, a partir de levantamento feito automaticamente pelo Twitter. 
diversas e, principalmente, enxergamos como grande contribuição do estudo a reflexão sobre a emergência de novas práticas de recepção e consumo de telenovela.

Segundo apontamos no tópico imediatamente anterior, essas práticas hoje são, em muito, agenciadas pelas redes sociais, que colocam em evidência os comentários dos receptores sobre as produções midiáticas que consomem - e reproduzem. Se, em 2006-2007, tais práticas estavam engatinhando - na época, com o pioneiro Orkut -, hoje se encontram consolidadas, sujeitas a índices de mensuração e utilizadas, da parte dos produtores, como mídias de fato - ou desdobramento do mainstream.

\section{REFERÊNCIAS BIBLIOGRÁFICAS}

CANCLINI, Néstor García. Consumidores e cidadãos: conflitos multiculturais da globalização. Rio de Janeiro: Editora UFRJ, 2006.

FIORIN, José Luiz. Linguagem e ideologia. São Paulo: Ática, 2005.

O regime de 1964: discurso e ideologia. São Paulo: Atual, 1988.

MAINGUENEAU, Dominique. Termos-chave da análise do discurso. Belo Horizonte: Ed. UFMG, 1998.

ORLANDI, Eni Puccinelli. Análise de discurso: princípios e procedimentos. Campinas: Pontes, 2007.

PRIMO, Alex. O aspecto relacional das interacões na Web 2.0. In: XXIX CONGRESSO BRASILEIRO DE CIENCIAS DA COMUNICAÇÃO, 2006, Brasília. Anais, 2006.

\section{REFERÊNCIAS ELETRÔNICAS}

NA TELINHA. Record lançará linha de produtos de "Rebelde". Disponível em: <http://natelinha.uol.com.br/noticias/2011/03/16/154442.php>. Acesso em: 16 mar. 2011.

REBELDE - primeira temporada da novela. EMI Music, 2006. 3 DVD (780 min.), son., color.

REBELDE - segunda temporada da novela. EMI Music, 2006. 3 DVD (780 min.), son., color.

REBELDE - terceira temporada da novela. EMI Music, 2007. 3 DVD (780 min.), son., color. 